\title{
Gender effect on the scapular 3D posture and kinematic in healthy subjects
}

\author{
C. Schwartz ${ }^{1}$, J.L. Croisier ${ }^{1,2}$, E. Rigaux ${ }^{1,2}$, O. Brüls ${ }^{1,4}$, V. Denoë1 $1^{1,3}$, B. Forthomme ${ }^{1,2}$
}

1. Laboratory of Human Motion Analysis - LAMH, University of Liège, Liège, Belgium

2. Department of Physical Medicine and Rehabilitation, University of Liège, Liège, Belgium

3. Department of Architecture, Geology, Environment and Constructions, University of Liège, Liège, Belgium

4. Department of Aerospace and Mechanical Engineering, University of Liège, Liège, Belgium

\section{Summary}

Populations considered for shoulder analysis are often composed of various ratios of men and women. It is consequently hypothesized that gender has no significant effect on the joint kinematic. However the literature reports, for the shoulder, differences in the range of motion between genders. The specific influence of gender on the scapulathoracic kinematics has not been studied yet. The dominant shoulder of two populations of men and women composed of 11 subjects each were evaluated in three dimensions for three distinct motions: flexion in the sagittal plane, abduction in the frontal plane and gleno-humeral internal/external rotation with the arm abducted at $90^{\circ}$. Posture, kinematics and range of motion were studied separately. For flexion and abduction and with regard to the scapular kinematic, external rotation were significantly larger for women than men. The differences were of at least $5^{\circ}$ at $120^{\circ}$ of humeral elevation. Upward rotations were identical. Women also showed larger average active humerothoracic range of motion. The mean differences were of $13^{\circ}, 7^{\circ}, 12^{\circ}$ and $5^{\circ}$ for abduction, flexion, internal rotation and external rotation, respectively. No difference was observed between the scapular resting positions of both populations. The observed differences concerning both the scapular and humeral patterns would indicate that the shoulder behavior of men and women should not be expected to be similar.

Keywords: shoulder; scapula; humerus; joint; motion analysis; gender; 3D 


\section{Introduction}

The scapulo-thoracic motion has been less studied than other joints because of the difficulty to accurately assess its motion. One common and noninvasive method is to use skin markers in association with an optoelectronic system. However the scapula greatly slides under the skin (Matsui et al., 2006) and make the interpretation of the measurements difficult. However, thanks to continuous efforts to standardize motion analysis protocol (Kontaxis et al., 2009; Wu et al., 2005), data reduction (Alexander and Andriacchi, 2001; Jacq et al., 2010; Roux et al., 2002), and error estimation studies (Karduna et al., 2001; Lempereur et al., 2010; Matsui et al., 2006; Schwartz et al., 2011), optoelectronic systems are now recognized as a valid tool to study scapula motion.

Studies in the literature provide the scapular motion of healthy subjects for several motions (McClure et al., 2001; VanAndel et al., 2008) and configurations (motion speed (Fayad et al., 2006), active vs. passive (Price et al., 2000)). It has also been shown that some characteristics such as age, gender and shoulder dominance (Barnes et al., 2001; Dayanidhi et al., 2005; Matsuki et al., 2011) induce variations in the shoulder motion. The specific effect of gender on shoulder motion is however not well documented yet. Barnes et al. (Barnes et al., 2001) studied the effect of gender on the soulder range of motion and measured a significantly greater range of motion for female subjects. However, the effect of gender on the scapular pattern has, to our knowledge, not been studied yet. It is important to know its influence in the case of a rehabilitation process or a preventive approach. Moreover, there is no common attitude in the literature regarding the gender composition of tested populations. In studies concerning either healthy or pathological subjects, it is regularly assumed that gender has no significant effect on scapular motion as the populations are composed of various ratios of men and women (Borstad, 2006; Ludewig et al., 2009; Yano et al., 2010). However some other studies select either equally mixed population (Ebaugh et al., 2005; McClure et al., 2006; McCully et al., 2005), which might be a good way to eliminate potential gender effect, or gender homogeneous population (Boone and Azen, 1979; Borstad and Ludewig, 2002; Price et al., 2000). In studies dealing with sport, this latter approach (Myers, 2005; Myklebust et al., 2011) or gender comparison (Owens et al., 2009; Reeser et al., 2010 ) is much more common, probably because gender has a recognized effect on performance. It is however not an universal rule either (Tucker et al., 2010).

Knowledge of the normal behavior of the scapula is of paramount importance in order to assess clinical pathologies, physiological adaptations, treatment or rehabilitation program effects. The aim of the present study is therefore to evaluate the effect of gender on the shoulder motion for healthy sedentary subjects. 


\section{Methods}

\section{Participants}

The study included 11 men (age: $22.4 \pm 2.5$ years; height: $1.80 \pm 0.05 \mathrm{~m}$; weight: $73 \pm 6$ $\mathrm{kg}$; BMI: $22.6 \pm 2.2 \mathrm{~kg} . \mathrm{m}^{-2}$ ) and 11 women (age: $22.2 \pm 1.8$ years; height: $1.69 \pm 0.07 \mathrm{~m}$; weight: $60 \pm 7 \mathrm{~kg}$; BMI: $21.0 \pm 1.5 \mathrm{~kg} \cdot \mathrm{m}^{-2}$ ). 8 men and 9 women were right-handed. None of the subjects have ever practiced, per week, more than 2 hours of a sport involving the upper limbs, suffered of kyphosis, scoliosis, had inequality of the lower limbs, and been subject to upper limbs or thoracic lesions and/or surgery. In addition, clinical tests (Rockwood et al., 2004) were performed by the same examiner to confirm that the volunteers do not suffer from any sub-coraco-acromial conflict (Neer, Hawkins and Yokum tests) and/or tendinous pathologies (Jobe, Patte, Palm up, Lift off tests). The subjects did not complain of any kind of shoulder pain. Each participant was informed of the details of the study and provided signed consent. The study was approved by the local medical ethics committee.

\section{Instrumentation}

The 3-dimensional position and orientation of the subjects' thorax and dominant scapula, humerus and forearm were tracked using four Codamotion CX1 units (Charnwood Dynamics, Rothley, UK) at a sampling rate of $100 \mathrm{~Hz}$. Eighteen active markers were used to follow the bony segments motion. Four markers on the thorax were placed with respect to the International Society of Biomechanics (ISB) recommendations (Wu et al., 2005). Six markers were placed on the upper posterior face of the scapula as proposed by Bourne (Bourne et al., 2011) (patch 4). Finally four markers were placed on the middle of the arm and four more on the forearm. Concerning the arm cluster, special care was made to avoid the deltoid muscle area.

\section{Experimental procedure}

The volunteers were in a standing position throughout the acquisitions. The bony landmarks listed by the ISB (Wu et al., 2005) were digitalized if no active marker were already present in order to express the results in the ISB anatomical based reference frames. Palpation was repeated three times to reduce intra-manipulator error (Schwartz et al., 2011a). The gleno-humeral head center was evaluated functionally using the method proposed by Gamage (Gamage and Lasenby, 2002).

The position at rest of the scapula was obtained during a static acquisition. The subjects were standing still with the hands along the body (neutral rotation of the humerus) (Groot, 1997). The subjects then performed 3 motions with their dominant side: elevation and lowering of the arm in the frontal plane (abduction plane) with the arm externally rotated, elevation and lowering of the arm in the sagittal plane (flexion plane) and gleno-humeral $(\mathrm{GH})$ internal/external rotation in the sagittal plane with the arm abducted at $90^{\circ}$ and the elbow kept flexed at $90^{\circ}$. Arm $90^{\circ}$ abduction was visually verified by the experimenter during the acquisitions. For each motion, the subjects moved actively their arm up to the maximal range of motion and five repetitions of each motion were collected. 
The volunteers had time to practice and get familiar with the motions before the acquisitions occurred. Subjects were instructed to perform active elevation or rotation at a self-selected but relatively slow speed (Fayad et al., 2006). They were also asked to avoid thoracic compensation when maximal amplitude was reached.

\section{Data reduction and analysis}

Scapular orientation was expressed relatively to the thorax using YXZ Cardan decomposition ( $\mathrm{Wu}$ et al., 2005). Humerus orientation, for the flexion and the abduction, was expressed relatively to the thorax using YXZ Cardan decomposition (Senk and Chèze, 2006) in order to avoid gimbal lock (Cappozzo et al., 2005) (mathematical indetermination when expressing the rotation angles). Ludewig et al. (Ludewig et al., 2002) reported that humeral internal/rotation is not well described for the GH internal/external rotation when using sensors placed on the arm. They measured errors of up to $15.6^{\circ}$ for internal rotations. Therefore we estimated the arm internal/external rotation as the angle defined by the forearm and the horizontal axis in the sagittal plane. As no motion occurred at the elbow joint during $\mathrm{GH}$ internal/external rotation, soft tissue artifacts were kept as small as possible. The scapular orientation was then expressed relatively to the humeral elevation/rotation.

Our goal was to study separately the influence of the initial position of the scapula and its kinematic. Therefore, scapular orientation and humeral elevation/rotation were set to $0^{\circ}$ for the starting position of each motion. In more details these positions were the arm along the body in a neutral position, the arm along the body and externally rotated of $90^{\circ}$ and the arm abducted by $90^{\circ}$ for the elevation/lowering of the arm in the sagittal plane, the elevation/lowering of the arm in the frontal plane and the internal/external rotation motion respectively. The more traditional presentation of the kinematic (i.e. without removing the stating position values) will also be presented as an illustration in order to give the reader the possibility to evaluate our methodology.

The obtained data were averaged first for each subject over the 5 repeated trials in order to limit motoric noise (Groot, 1997) and then over each population for every degree increment of humeral elevation/rotation. Both elevation and lowering of the arm were performed by the subjects. As Borstad et al. (Borstad and Ludewig, 2002) measured small but statistically significant differences between these two phases, both were kept and merged for analysis. Because all volunteers did not achieve the same range of motion, scapular kinematic results are only expressed up to the lowest maximal range achieved in both populations for the GH internal/external rotation of the shoulder. As the accuracy of measurements based on skin markers decrease rapidly after $120^{\circ}$ of humeral elevation (Karduna et al., 2001), the other 2 motions (elevation and lowering of the arm in the frontal and sagittal plane) are given from $0^{\circ}$ to $120^{\circ}$ of humerus elevation.

Three main results are provided in this paper for each population: scapular position at rest, scapular kinematics for the three motions and finally the humero-thoracic range of motion also for the three motions. 
Published in Clinical Physiology and Functional Imaging

http://onlinelibrary.wiley.com/journal/10.1111/\%28ISSN\%291475-097X

\section{Statistical analysis}

Descriptive statistics (mean and standard deviation [SD]) of the scapular kinematic were calculated for each step of $1^{\circ}$. Descriptive statistics of the scapular resting position as well as the humeral range of motion (ROM) were also evaluated. For the statistical analysis, the level of significance was set at $\mathrm{p}<0.05$. Unpaired two-sample $t$-tests were used to compare the scapular resting position, the incremental data of the scapular angles and the humero-thoracic range of motion between the male and female populations. Data processing and plotting were realized using open-source scientific python tools (Hunter, 2007; Jones et al., 2001; Perez and Granger, 2007). The size of the groups was chosen to detect $5^{\circ}$ differences with a power of $70 \%$. 


\section{Results}

No significant differences were found for the scapular position at rest between the male and female populations (Figure 1). However women present larger upward rotation $\left(4.5 \pm 5.5^{\circ}\right.$ vs. $\left.0.5 \pm 6.5^{\circ}\right)$ and internal rotation $\left(34 \pm 12^{\circ}\right.$ vs. $\left.29 \pm 7^{\circ}\right)$ than men. Similar anterior tilts were measured $\left(8 \pm 4.5^{\circ}\right.$ and $\left.9 \pm 3.5^{\circ}\right)$.

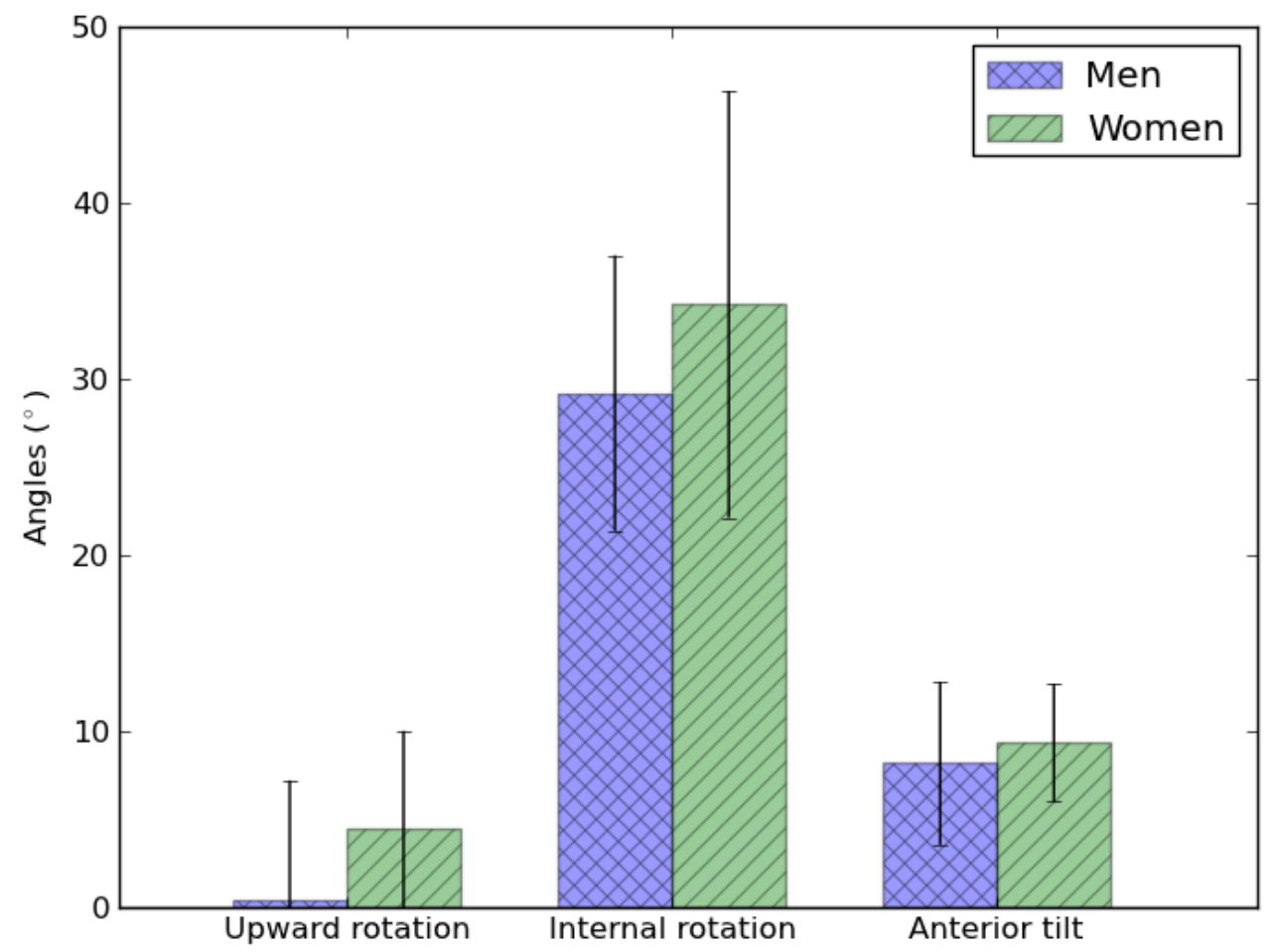

Figure 1 - Scapular orientation at rest (mean and standard deviation) for male (crossed diagonal hatching) and female (diagonal hatching) populations.

Several significant differences are observed between the scapular motion between male and female populations in this study when the influence of the initial position is removed (Figure 2). All occur for the external/internal rotation of the scapula. During the active motion of the arm in the frontal and sagittal planes, the scapula goes more externally in the female population. In terms of amplitude, the difference between the 2 populations is equal to $6-7^{\circ}$ at $120^{\circ}$ of humeral elevation. It is also worth noting that no significant differences are observed concerning the scapula kinematic during the $\mathrm{GH}$ internal/external rotation with the arm abducted at $90^{\circ}$.

When the influence of the initial position is kept (Figure 3), the main observation concerns the more posterior tilt of the scapula in the male population for all three motions. In the sagittal plane and during the internal/external rotation, we also observe that the scapula in the male population has a larger upward rotation. 

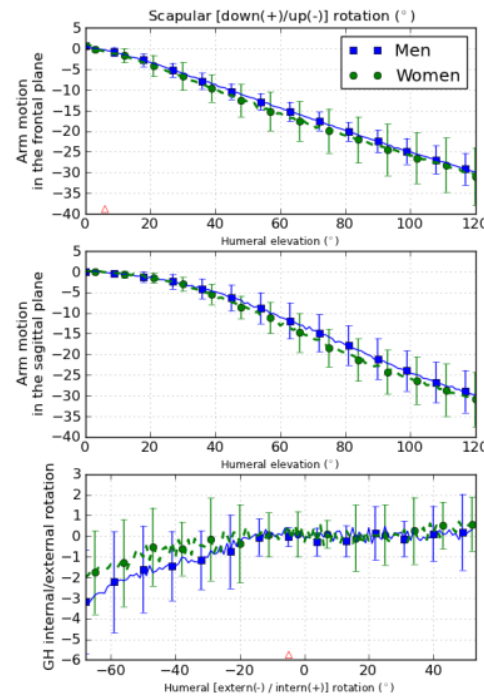
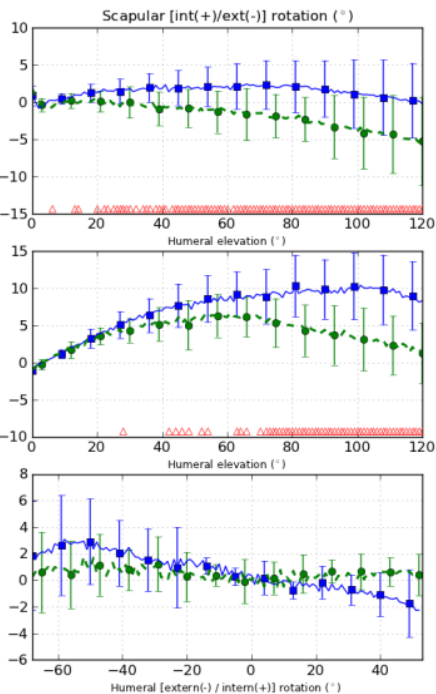
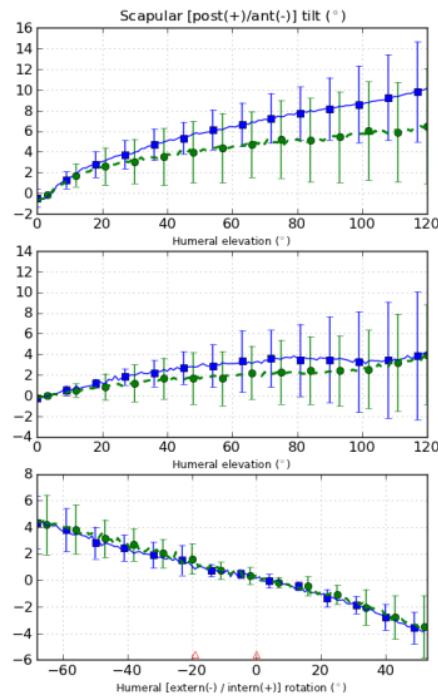

Figure 2 - Scapular rotations (mean and standard deviation) with respect to humeral elevation/rotation relatively to the thorax (by columns) with the initial postural offset removed: upward/downward rotation, external/internal rotation, posterior/anterior tilt for three motions (by rows): motion of the arm in the frontal plane, motion of the arm in the sagittal plane and internal/external rotation at $90^{\circ}$ of abduction for male (squares) and female (circles) populations. Significant differences $(\mathrm{p}<0.05)$ between the two populations at a specific humeral elevation/rotation are marked by an empty triangle along the $\mathrm{x}$-axis.
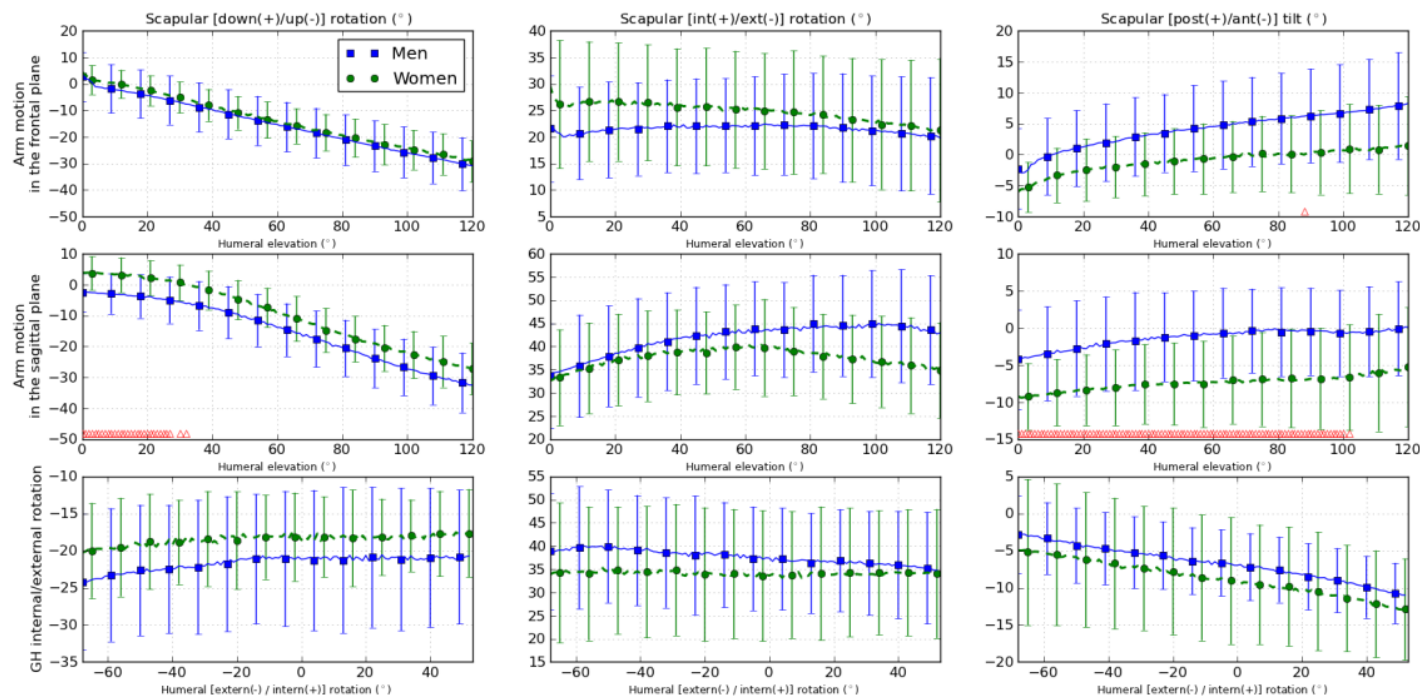

Figure 3 - Scapular rotations (mean and standard deviation) with respect to humeral elevation/rotation relatively to the thorax (by columns) with the initial postural offset kept: upward/downward rotation, external/internal rotation, posterior/anterior tilt - for three motions (by rows): motion of the arm in the frontal plane, motion of the arm in the sagittal plane and internal/external rotation at $90^{\circ}$ of abduction for male (squares) and female (circles) populations. Significant differences $(\mathrm{p}<0.05)$ between the two populations at a specific humeral elevation/rotation are marked by an empty triangle along the $\mathrm{x}$-axis. 
Female subjects have greater arm active range of motion (Figure 4) for all studied motions and significant differences are observed for the maximal abduction $(\mathrm{p}=0.017)$ and the maximal internal rotation $(\mathrm{p}=0.017)$. Mean maximal abduction for men is equal to $152 \pm 12^{\circ}$ against $165 \pm 10^{\circ}$ for women. Mean men maximal sagittal flexion is equal to $150 \pm 10^{\circ}$ while mean women maximal flexion is higher and equal to $157 \pm 6^{\circ}$. Concerning internal rotation, men achieve a mean value of $69 \pm 11^{\circ}$ against $81 \pm 10^{\circ}$ for women. Finally, the mean maximal external rotation of men, equal to $84 \pm 12^{\circ}$, is again lower than women who achieve $89 \pm 8^{\circ}$ of rotation.

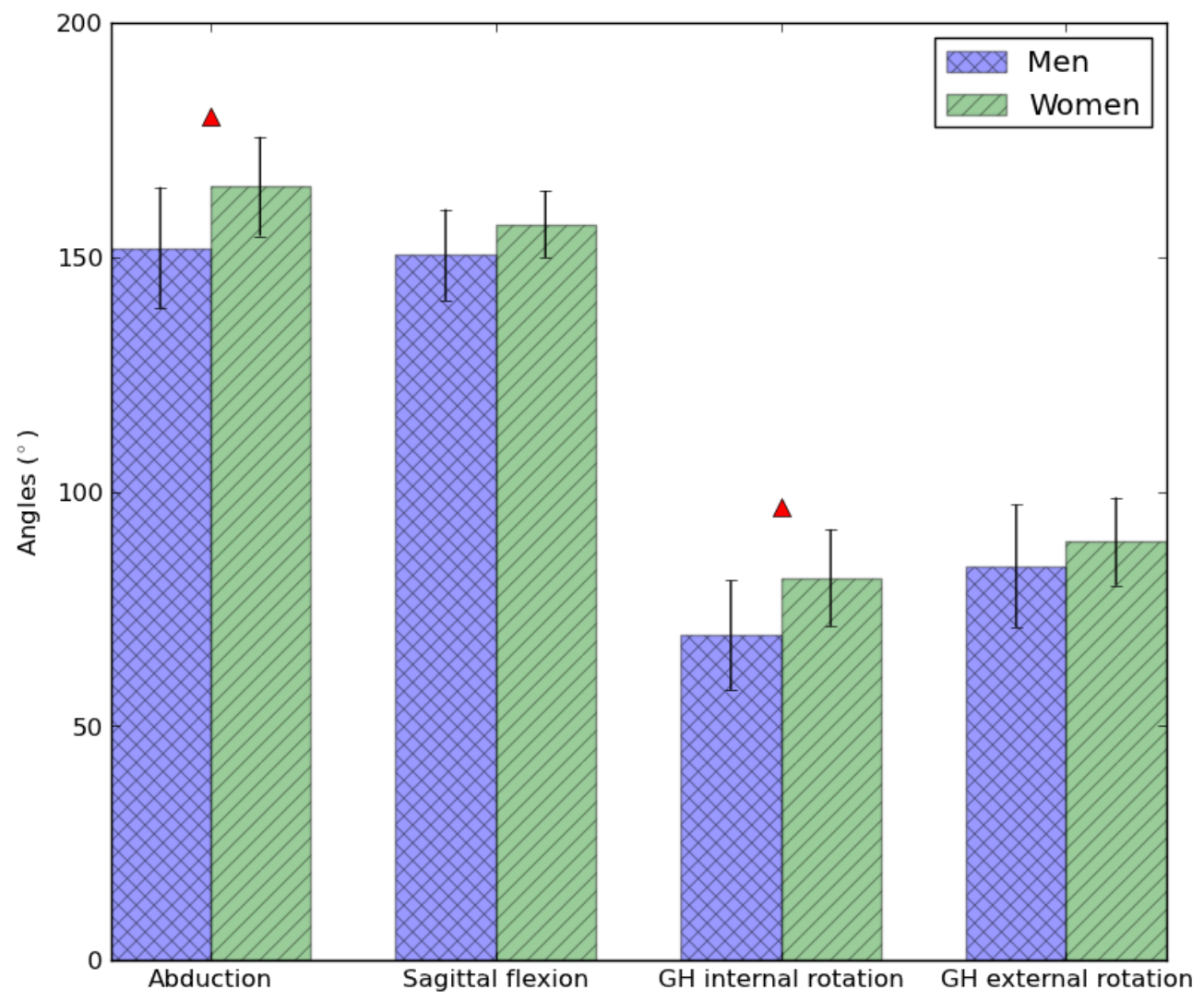

Figure 4 - Humero-thoracic range of motion (mean and standard deviation) for male (crossed diagonal hatching) and female (diagonal hatching) populations. Significant differences $(p<0.05)$ between the two populations are marked by an empty triangle above the results. 


\section{Discussion}

The aim of the present paper was to compare the 3D shoulder motion of healthy male and female populations. The comparison was based on the active range of motion of the shoulder as well as the posture (resting position) and the kinematics of the scapula.

Several studies in the literature provide estimations of the range of motion of the shoulder. These results are summarized in Table 1. Most studies have used goniometers. This tool has the advantage to be easy to use. However, inter-observer reproducibility might not be as good as 3D measurements and more importantly it could be difficult to assess for the thoracic motion participation, which usually happens at maximal shoulder excursion. This might explain why most studies using this technique report larger ranges of motion than in this paper However, in our study, the scapula motion was not restrained and was able to move anteriorly, which may explain some differences for the internal/external rotation motion.

For all active motions, women present a larger humero-thoracic range of motion. Previous studies have already showed that, among other parameters, women tend to be more lax (Remvig et al., 2007; Silman et al., 1987). On a large cohort of students entering military academy, Vairo et al. (Vairo et al., 2012) measured significant differences between maximal flexion in the male and female populations. For external/internal rotations, Vairo et al. (Vairo et al., 2012) found no significant differences between male and female but still measured higher range of motion for the female population. Similarly, Barnes et al. (Barnes et al., 2001) found larger range of motion for women than men. Passive elements (tightness of the shoulder capsule, coraco-humeral and gleno-humeral ligaments) limit the gleno-humeral joint rotation in extreme motions. Joint larger mobility may be linked to increased ligamentous laxity in the female population (Remvig et al., 2007). Scapulo-humeral stabilization is also performed by active elements (including the muscles of the rotator cuff). Male larger muscles strength (Danneskiold-Samsøe et al., 2009; Stoll et al., 2000) and mass around the shoulder are also believed to decrease joint laxity when considering sedentary subjects.

In the present study, the scapula at rest has globally a limited upward rotation, is internally rotated and presents a small anterior tilt. Even if no previous study has compared specifically male and female populations, prior results have been presented for mixed populations. Borstad et al. (Borstad, 2006) studied the resting position of the scapula for populations having long and short pectoralis minor muscle resting length. The scapula was more internally and posteriorly rotated than in our study. However it is not clear how anatomical axes were defined. Ludewig et al. (Ludewig et al., 2009) and Watson et al. (Watson et al., 2005) found an upward rotation of the scapula similar to our results. The scapula in the female population was measured to be $4^{\circ}$ more upward and $5^{\circ}$ more internally rotated. However, the resting positions of male and female populations are not found to be significantly different. This result might be due to a lack of power of the study. 
The estimation of the kinematic of the scapula using skin markers is particularly difficult because of the large relative motion of the skin and the bone (Matsui et al., 2006). It is the main limitation of such analyzes. However validation studies tend to demonstrate that scapular motion can be accurately estimated for humeral elevation inferior to $120^{\circ}$ for elevation in the sagittal plane (Karduna et al., 2001; Lempereur et al., 2010). Our own measurements in the sagittal and frontal plane are therefore only presented up to $120^{\circ}$ of humeral flexion. Other authors report that bone motion is usually underestimated with skin-fixed sensors/markers (Meskers et al., 2007). Using bone pins, Ludewig et al. (Ludewig et al., 2009) measured larger upward rotation $\left(40^{\circ}\right.$ vs. $\left.32^{\circ}\right)$ and posterior tilt $\left(18^{\circ}\right.$ vs. $\left.6^{\circ}-11^{\circ}\right)$ than our measurements for an humeral elevation in the frontal plane. It has also been previously emphasized that measurements are very sensitive to markers placement (Bourne et al., 2011). Following the recommendations of Bourne et al. (Bourne et al., 2011), we used the scapular markers configuration which seems to be overall (for the 3 scapular rotations) the most accurate. Comparison of measurements across studies is difficult because of differences in the protocols, measurement techniques, and population characteristics differences. However thanks to standardization efforts realized in the biomechanics community ( $\mathrm{Wu}$ et al., 2005), recent studies are now easier to compare. Results of previous studies for different men/women ratios are summarized in Table 2.

Differences observed in the scapular pattern between male and female populations have not been reported before. In this study, the scapula was found to be significantly more externally rotated in the female population for the active motion of the arm in both the frontal and sagittal planes. Several studies have observed morphological and motor control strategies differences between genders. Several anatomical differences (Krobot et al., 2009) were described. These differences include global anthropometrical variations (segment lengths, masses) (Winter, 2009) and more local variations such as the shapes of the acromion (Paraskevas et al., 2008), the glenoid (Merrill et al., 2009) and the chest (Bellemare et al., 2003). These variations imply modified muscle arms for several important muscles of the shoulder (deltoid, trapezius) and inertial properties of the bone segments. This could possibly lead to altered muscle recruitments and scapular motions. The muscles recruitment has been hypothesized to be a compromise between the postural positioning error, the optimal stabilization of the joint (Myers and Lephart, 2000) (which result in muscles co-activation) and a limited energy consumption (Gribble et al., 2003). Experimental measurements of shoulder muscles activations have shown differences between healthy men and women (Anders et al., 2004); men show superior muscles activations in the main force direction. Finally, the male larger muscles strength (Danneskiold-Samsøe et al., 2009; Stoll et al., 2000) may also lead to scapular motion modifications. Men anterior muscles (pectoralis minor and major) are usually more developed and shortened. It could explain the less external rotation observed in the male population. Likewise, the fact that women showed less posterior tilt during active motion of the arm in the frontal and sagittal planes could entail a superior contact between the acromial surface and the superior rotator cuff. This position of the scapula during active motion may result from shortened pectoralis minor and less scapular muscles recruitment.

The differences of the kinematic between men and women are probably the consequence of various parameters. Musculoskeletal modeling (Damsgaard et al., 2006; 
Delp et al., 2007; Sandholm et al., 2011) may facilitate the investigation of the origin of these differences. Indeed, musculoskeletal modeling is a mechanical description of (at least) bony segments, joints and muscles. It would therefore be possible to study independently each parameter of interest, which is usually impossible in-vivo because the inter-subject variability never affects one single parameter at a time. Electromyographic measurements as well as isokinetic measurements would give additional insights and understanding of the activation strategies underlying the scapular kinematic and the scapular muscle strength influence.

In the present study no guides were used to secure the motion of the subjects in the various planes. We took several precautions to ensure the reliability of our tests: (i) the motions were in anatomical planes (sagittal, frontal), (ii) two testers were always present during the tests: while the first one was in charge of the technical part of the acquisition, the second one checked visually that the motions were done correctly, (iii) the subjects practiced the motions before the measurements, (iv) the subjects performed the motions at their self chosen speed and (v) for each subject and each motion, 5 repetitions were measured and then averaged in order to limit motoric noise. However the absence of guide may still have increased the variability of the measures. It is especially true for the gleno-humeral internal/external rotation with the arm abducted at $90^{\circ}$. The absence of differences between sexes in this specific motion may be explained by this limitation. 


\section{Conclusion}

The scapular motion of male and female population has not been compared before in the literature. Their motion was however indirectly hypothesized to be similar. The present study demonstrates that the kinematic and the range of motion of the shoulder should be expected to be different between men and women. Such results were only reported concerning the gleno-humeral joint but not concerning the scapula-thoracic one. Clinically speaking, knowledge of gender specificities could help further studies to identify symptomatic kinematic patterns. We would also advise that special care is given to the gender composition of populations during research studies. 
Published in Clinical Physiology and Functional Imaging

http://onlinelibrary.wiley.com/journal/10.1111/\%28ISSN\%291475-097X

\section{Acknowledgements:}

This work was partly supported by the Fédération Wallonie-Bruxelles (Belgium).

\section{Conflict of interest}

The authors do not have any propriety, financial, professional or other personal interest of any nature in any product, service and/or company that could influence the position presented in this manuscript. 
Published in Clinical Physiology and Functional Imaging

http://onlinelibrary.wiley.com/journal/10.1111/\%28ISSN\%291475-097X

\section{References}

Alexander, E.J., Andriacchi, T.P. Correcting for deformation in skin-based marker systems. J Biomech (2001); 34: 355-61.

Anders, C., Bretschneider, S., Bernsdorf, A., Erler, K., Schneider, W. Activation of shoulder muscles in healthy men and women under isometric conditions. $J$ Electromyogr Kinesiol (2004); 14: 699-707.

Barnes, C.J., Van Steyn, S.J., Fischer, R.A. The effects of age, sex, and shoulder dominance on range of motion of the shoulder. J shoulder Elb Surg (2001); 10: 242-6.

Bellemare, F., Jeanneret, A., Couture, J. Sex differences in thoracic dimensions and configuration. Am J Respir Crit Care Med (2003); 168: 305-12.

Boone, D.C., Azen, S.P. Normal range of motion of joints in male subjects. J Bone Joint Surg Am (1979); 61: 756-9.

Borstad, J. Resting position variables at the shoulder: evidence to support a postureimpairment association. Phys Ther (2006); 86: 549-557.

Borstad, J.D., Ludewig, P.M.Comparison of scapular kinematics between elevation and lowering of the arm in the scapular plane. Clin Biomech (Bristol, Avon) (2002); 17: $650-9$.

Bourne, D.A., Choo, A.M., Regan, W.D., Macintyre, D.L., Oxland, T.R. The Placement of Skin Surface Markers for Non-Invasive Measurement of Scapular Kinematics Affects Accuracy and Reliability. Ann Biomed Eng (2011); 39: 777785 .

Cappozzo, A., Della Croce, U., Leardini, A., Chiari, L. Human movement analysis using stereophotogrammetry. Part 1: theoretical background. Gait Posture (2005); 21: 186-96.

Damsgaard, M., Rasmussen, J., Christensen, S.T., Surma, E., de Zee, M. Analysis of musculoskeletal systems in the AnyBody Modeling System. Simul Model Pract Theory (2006); 14: 1100-1111.

Danneskiold-Samsøe, B., Bartels, E.M., Bülow, P.M., et al. Isokinetic and isometric muscle strength in a healthy population with special reference to age and gender. Acta Physiol (2009); 197 Suppl: 1-68.

Dayanidhi, S., Orlin, M., Kozin, S., Duff, S., Karduna, A. Scapular kinematics during humeral elevation in adults and children. Clin Biomech (Bristol, Avon) (2005); 20: $600-6$. 
Delp, S.L., Anderson, F.C., Arnold, A.S., et al. OpenSim : Open-Source Software to Create and Analyze Dynamic Simulations of Movement. IEEE Trans Biomed Eng (2007); 54: 1940-1950.

Ebaugh, D.D., McClure, P.W., Karduna, A.R. Three-dimensional scapulothoracic motion during active and passive arm elevation. Clin Biomech (Bristol, Avon) (2005); 20: 700-9.

Fayad, F., Hoffmann, G., Hanneton, S., et al. $\quad 3-D$ scapular kinematics during arm elevation: effect of motion velocity. Clin Biomech (Bristol, Avon) (2006); 21: 932-41.

Gamage, S.S.H.U., Lasenby, J. New least squares solutions for estimating the average centre of rotation and the axis of rotation. J Biomech (2002); 35: 87-93.

Gribble, P.L., Mullin, L.I., Cothros, N., Mattar, A. Role of cocontraction in arm movement accuracy. J Neurophysiol (2003); 89: 2396-405.

Groot, H. De The variability of shoulder by means of palpation motions recorded. Clin Biomech (Bristol, Avon) (1997); 12: 461-472.

Hunter, J. Matplotlib: a 2D graphics environment. Comput Sci Eng (2007); 9: 9095.

Jacq, J.-J., Schwartz, C., Burdin, V., et al. Building and tracking root shapes. IEEE Trans Biomed Eng (2010); 57: 696-707.

Jones, E., Oliphant, T., Peterson, P. SciPy: Open source scientific tools for Python [WWW Document]. http//www scipy org/ (2001): 2001.

Karduna, A.R., McClure, P.W., Michener, L. a., Sennett, B. $\quad$ Dynamic Measurements of Three-Dimensional Scapular Kinematics: A Validation Study. $J$ Biomech Eng (2001); 123: 184.

Kibler, W. The role of the scapula in athletic shoulder function. Am J Sports Med (1998); 26.

Kontaxis, A., Cutti, A.G., Johnson, G.R., Veeger, H.E.J. A framework for the definition of standardized protocols for measuring upper-extremity kinematics. Clin Biomech (Bristol, Avon) (2009); 24: 246-53.

Krobot, A., Janura, M., Elfmark, M. Functional categorization of the individual morphology of the scapula. Med Biol Eng Comput (2009); 47: 497-506.

Lempereur, M., Brochard, S., Burdin, V., Rémy-Néris, O. Difference between palpation and optoelectronics recording of scapular motion. Comput Methods Biomech Biomed Engin (2010); 13: 49-57. 
Ludewig, P.M., Cook, T.M., Shields, R.K. Comparison of Surface Sensor and BoneFixed Measurement of Humeral Motion. J Appl Biomech (2002); 18: 163-170.

Ludewig, P.M., Phadke, V., Braman, J.P., Hassett, D.R., Cieminski, C.J., LaPrade, R.F. Motion of the shoulder complex during multiplanar humeral elevation. $J$ Bone Joint Surg Am (2009); 91: 378-89.

Matsui, K., Shimada, K., Andrew, P.D. Deviation of skin marker from bone target during movement of the scapula. J Orthop Sci (2006); 11: 180-4.

Matsuki, K., Matsuki, K.O., Mu, S., et al. In vivo 3-dimensional analysis of scapular kinematics: comparison of dominant and nondominant shoulders. J shoulder Elb Surg (2011); 20: 659-65.

McClure, P., Michener, L., Karduna, A. Shoulder function and 3-dimensional scapular kinematics in people with and without shoulder impingement syndrome. Phys Ther (2006); 86: 1075-1090.

McClure, P.W., Michener, L.A., Sennett, B.J., Karduna, A.R. Direct 3-dimensional measurement of scapular kinematics during dynamic movements in vivo. $J$ shoulder Elb Surg (2001); 10: 269-77.

McCully, S.P., Kumar, N., Lazarus, M.D., Karduna, A.R. Internal and external rotation of the shoulder: effects of plane, end-range determination, and scapular motion. $J$ shoulder Elb Surg (2005); 14: 602-10.

Merrill, A., Guzman, K., Miller, S.L. $\quad$ Gender differences in glenoid anatomy: an anatomic study. Surg Radiol Anat (2009); 31: 183-9.

Meskers, C.G., van De Sande, M.A., de Groot, J.H.Comparison between tripod and skin-fixed recording of scapular motion. J Biomech (2007); 40: 941-6.

Myers, J.B. Scapular Position and Orientation in Throwing Athletes. Am J Sports Med (2005); 33: 263-271.

Myers, J.B., Lephart, S.M. The Role of the Sensorimotor System in the Athletic Shoulder. J Athl Train (2000); 35: 351-363.

Myklebust, G., Hasslan, L., Bahr, R., Steffen, K. High prevalence of shoulder pain among elite Norwegian female handball players. Scand J Med Sci Sports (2011): $1-7$.

Owens, B.D., Agel, J., Mountcastle, S.B., Cameron, K.L., Nelson, B.J. Incidence of glenohumeral instability in collegiate athletics. Am J Sports Med (2009); 37: $1750-4$. 
Paraskevas, G., Tzaveas, A., Papaziogas, B., Kitsoulis, P., Natsis, K., Spanidou, S. Morphological parameters of the acromion. Folia Morphol (Warsz) (2008); 67: 255-60.

Perez, F., Granger, B. IPython: a system for interactive scientific computing. Comput Sci Eng (2007); 9.

Price, C.I., Franklin, P., Rodgers, H., Curless, R.H., Johnson, G.R. $\quad$ Active and passive scapulohumeral movement in healthy persons: a comparison. Arch Phys Med Rehabil (2000); 81: 28-31.

Reeser, J.C., Joy, E. a, Porucznik, C. a, Berg, R.L., Colliver, E.B., Willick, S.E. Risk factors for volleyball-related shoulder pain and dysfunction. PM R (2010); 2: $27-$ 36.

Remvig, L., Jensen, D. V, Ward, R.C. Epidemiology of general joint hypermobility and basis for the proposed criteria for benign joint hypermobility syndrome: review of the literature. J Rheumatol (2007); 34: 804-9.

Rockwood, C.A., Matsen, F.A., Wirth, M.A., Lippitt, S.B. The Shoulder, 3rd ed. (3rd ed) (2004); pp.791-825. Saunders

Roux, E., Bouilland, S., Godillon-Maquinghen, A.-P., Bouttens, D. Evaluation of the global optimisation method within the upper limb kinematics analysis. $J$ Biomech (2002); 35: 1279-83.

Sandholm, A., Schwartz, C., Pronost, N., Zee, M., Voigt, M., Thalmann, D. Evaluation of a geometry-based knee joint compared to a planar knee joint. Vis Comput (2011); 27: 161-171.

Schwartz, C., Fedrigo, T., Brüls, O., et al. Reproducibility and repeatability of upper limb landmarks palpation for junior operators. In: Proceedings of the XXIIIth Congress of the ISB. Brussels; 2011.

Schwartz, C., Leboeuf, F., Rémy-Néris, O., Brochard, S., Lempereur, M., Burdin, V. Detection of incoherent joint state due to inaccurate bone motion estimation. Comput Methods Biomech Biomed Engin (2011): 37-41.

Senk, M., Chèze, L. Rotation sequence as an important factor in shoulder kinematics. Clin Biomech (Bristol, Avon) (2006); 21 Suppl 1: S3-8.

Silman, A.J., Day, S.J., Haskard, D.O. Factors associated with joint mobility in an adolescent population. Ann Rheum Dis (1987); 46: 209-12.

Stoll, T., Huber, E., Seifert, B., Michel, B., Stucki, G. Maximal isometric muscle strength: normative values and gender-specific relation to age. Clin Rheumatol (2000): 105-113. 
Tucker, W.S., Armstrong, C.W., Gribble, P. a, Timmons, M.K., Yeasting, R. a Scapular muscle activity in overhead athletes with symptoms of secondary shoulder impingement during closed chain exercises. Arch Phys Med Rehabil (2010); 91: 550-6.

Vairo, G.L., Duffey, M.L., Owens, B.D., Cameron, K.L. Clinical descriptive measures of shoulder range of motion for a healthy, young and physically active cohort. Sports Med Arthrosc Rehabil Ther Technol (2012); 4: 33.

VanAndel, C.J., Wolterbeek, N., Doorenbosch, C.A.M., Veeger, D.H.E.J., Harlaar, J. Complete 3D kinematics of upper extremity functional tasks. Gait Posture (2008); 27: 120-7.

Watson, L., Balster, S.M., Finch, C., Dalziel, R. Measurement of scapula upward rotation: a reliable clinical procedure. Br J Sports Med (2005); 39: 599-603.

Winter, D.A. Anthropometry. In: Biomechanics and Motor Control of Human Movement (2009); 4th ed John Wiley \& Sons; 82-106.

Wu, G., Vanderhelm, F., Dirkjanveeger, H., et al. ISB recommendation on definitions of joint coordinate systems of various joints for the reporting of human joint motion - Part II: shoulder, elbow, wrist and hand. J Biomech (2005); 38: 981992.

Yano, Y., Hamada, J., Tamai, K., et al. Different scapular kinematics in healthy subjects during arm elevation and lowering: glenohumeral and scapulothoracic patterns. J Shoulder Elbow Surg (2010); 19: 209-15. 
Published in Clinical Physiology and Functional Imaging

http://onlinelibrary.wiley.com/journal/10.1111/\%28ISSN\%291475-097X

Table 1 - Humeral range of motion measured by various authors

\begin{tabular}{|c|c|c|c|c|}
\hline Author & Instrumentation & $\begin{array}{c}\text { Proportion } \\
\text { of men in the } \\
\text { population } \\
(\%)\end{array}$ & $\begin{array}{c}\text { Active } \\
\text { shoulder } \\
\text { motion }\end{array}$ & $\begin{array}{l}\text { Range of } \\
\text { motion }\left({ }^{\circ}\right)\end{array}$ \\
\hline \multirow{2}{*}{$\begin{array}{c}\text { Boone et al., } \\
1979 \text { (Boone } \\
\text { and Azen, 1979) }\end{array}$} & \multirow[b]{2}{*}{ Goniometer } & \multirow[b]{2}{*}{$100 \%$} & Abd & $170^{\circ}$ \\
\hline & & & Flex & $158^{\circ}$ \\
\hline \multirow{4}{*}{$\begin{array}{c}\text { Barnes et al. } \\
2001 \text { (Barnes et } \\
\text { al., 2001) }\end{array}$} & \multirow{4}{*}{ Goniometer } & \multirow{4}{*}{$\varnothing$} & Abd & $\begin{array}{l}\text { Female: } 187.6^{\circ} \\
\text { Male: } 180.1^{\circ}\end{array}$ \\
\hline & & & Flex & $\begin{array}{l}\text { Female: } 176.7^{\circ} \\
\text { Male: } 173.6^{\circ}\end{array}$ \\
\hline & & & GH int & $\begin{array}{c}\text { Female: } 47.5^{\circ} \\
\text { Male: } 41.2^{\circ}\end{array}$ \\
\hline & & & GH ext & $\begin{array}{l}\text { Female: } 104.9^{\circ} \\
\text { Male: } 101.2^{\circ} \\
\end{array}$ \\
\hline \multirow{2}{*}{$\begin{array}{c}\text { McClully et al., } \\
2005 \text { (McCully } \\
\text { et al., 2005) }\end{array}$} & \multirow{2}{*}{$\begin{array}{l}\text { Custom-made } \\
\text { splint }\end{array}$} & \multirow[b]{2}{*}{$50 \%$} & GH int & $73^{\circ}$ \\
\hline & & & $\mathrm{GH}$ ext & $107^{\circ}$ \\
\hline \multirow{3}{*}{$\begin{array}{c}\text { McCLure et al., } \\
2006 \text { (McClure } \\
\text { et al., 2006) }\end{array}$} & \multirow{3}{*}{ Goniometer } & \multirow{3}{*}{$53 \%$} & Flex & $163,5^{\circ}$ \\
\hline & & & GH int & $70^{\circ}$ \\
\hline & & & GH ext & $112^{\circ}$ \\
\hline \multirow{3}{*}{$\begin{array}{l}\text { Vairo et al., } \\
2012 \text { (Vairo et } \\
\text { al., 2012) }\end{array}$} & \multirow{3}{*}{ Goniometer } & \multirow{3}{*}{$\varnothing$} & Flex & $\begin{array}{c}\text { Female: } 168.1^{\circ} \\
\text { Male: } 165.2^{\circ}\end{array}$ \\
\hline & & & GH int & $\begin{array}{c}\text { Female: } 56.0^{\circ} \\
\text { Male: } 54.5^{\circ}\end{array}$ \\
\hline & & & GH ext & $\begin{array}{c}\text { Female: } 100.1^{\circ} \\
\text { Male: } 98.6^{\circ}\end{array}$ \\
\hline \multirow{4}{*}{ Our study } & \multirow{4}{*}{$\begin{array}{c}\text { Optoelectronic } \\
\text { system }\end{array}$} & \multirow{4}{*}{$\varnothing$} & Abd & $\begin{array}{c}\text { Female: } 165^{\circ} \\
\text { Male: } 152^{\circ}\end{array}$ \\
\hline & & & Flex & $\begin{array}{c}\text { Female: } 157^{\circ} \\
\text { Male: } 150^{\circ}\end{array}$ \\
\hline & & & GH int & $\begin{array}{c}\text { Female: } 81^{\circ} \\
\text { Male: } 69^{\circ}\end{array}$ \\
\hline & & & $\mathrm{GH}$ ext & $\begin{array}{c}\text { Female: } 89^{\circ} \\
\text { Male: } 84^{\circ}\end{array}$ \\
\hline
\end{tabular}


Table 2 - Amplitude of scapular rotations measured by various authors. In the frontal and sagittal planes, the arm elevation ranges from $0^{\circ}$ to $120^{\circ}$, and for the $\mathrm{GH}$ shoulder external/internal rotation, the shoulder rotation ranges from $70^{\circ}$ of extern rotation to $50^{\circ}$ of internal rotation (unless stated otherwise).

\begin{tabular}{|c|c|c|c|c|}
\hline Author & Instrumentation & $\begin{array}{c}\text { Proportion } \\
\text { of men in } \\
\text { the } \\
\text { population } \\
(\%)\end{array}$ & $\begin{array}{c}\text { Active } \\
\text { shoulder } \\
\text { motion }\end{array}$ & $\begin{array}{c}\text { Scapular rotation } \\
\left(\left(^{\circ}\right)\right.\end{array}$ \\
\hline \multirow{2}{*}{$\begin{array}{c}\text { McClure et } \\
\text { al. } 2001\end{array}$} & \multirow{2}{*}{ Bone pins } & \multirow{2}{*}{$63 \%$} & Sag_low & $\begin{array}{l}31^{\circ} \text { upward rotation } \\
10^{\circ} \text { posterior tilt } \\
0^{\circ} \text { external rotation }\end{array}$ \\
\hline & & & GH ext/int rot & $\begin{array}{l}17^{\circ} \text { downward rotation } \\
15^{\circ} \text { anterior tilt } \\
14^{\circ} \text { internal rotation }\end{array}$ \\
\hline \multirow{2}{*}{$\begin{array}{c}\text { McClure et } \\
\text { al. } 2006\end{array}$} & \multirow{2}{*}{$\begin{array}{l}\text { Electromagnetic } \\
\text { system }\end{array}$} & \multirow[b]{2}{*}{$53 \%$} & Sag_elev & $\begin{array}{l}40^{\circ} \text { upward rotation } \\
2^{\circ} \text { anterior tilt } \\
0^{\circ} \text { external rotation } \\
\end{array}$ \\
\hline & & & $\begin{array}{l}\text { GH int/ext rot } \\
\text { unknown max } \\
\text { internal to } 80^{\circ} \\
\text { external rotation } \\
\end{array}$ & $\begin{array}{l}15^{\circ} \text { upward rotation } \\
14^{\circ} \text { posterior tilt } \\
16^{\circ} \text { external rotation }\end{array}$ \\
\hline \multirow{2}{*}{$\begin{array}{l}\text { Ludewig et } \\
\text { al. } 2009\end{array}$} & \multirow{2}{*}{ Bone pins } & \multirow{2}{*}{$60 \%$} & $\begin{array}{l}\text { Mean of } \\
\text { Front_elev and } \\
\text { Front_low }\end{array}$ & $\begin{array}{l}40^{\circ} \text { upward rotation } \\
18^{\circ} \text { posterior tilt } \\
0^{\circ} \text { external rotation }\end{array}$ \\
\hline & & & $\begin{array}{c}\text { Mean of } \\
\text { Sag_elev and } \\
\text { Sag_low }\end{array}$ & $\begin{array}{l}36^{\circ} \text { upward rotation } \\
20^{\circ} \text { posterior tilt } \\
0^{\circ} \text { external rotation }\end{array}$ \\
\hline \multirow{3}{*}{$\begin{array}{l}\text { Our study } \\
\text { - Men - }\end{array}$} & \multirow{3}{*}{$\begin{array}{l}\text { Optoelectronic } \\
\text { system }\end{array}$} & \multirow{3}{*}{$100 \%$} & Front & $\begin{array}{l}30^{\circ} \text { upward rotation } \\
10^{\circ} \text { posterior tilt } \\
0^{\circ} \text { external rotation }\end{array}$ \\
\hline & & & Sag & $\begin{array}{l}30^{\circ} \text { upward rotation } \\
4^{\circ} \text { posterior tilt } \\
8^{\circ} \text { internal rotation }\end{array}$ \\
\hline & & & $\mathrm{GH}$ rot & $\begin{array}{l}4^{\circ} \text { downward rotation } \\
8^{\circ} \text { anterior tilt } \\
4^{\circ} \text { external rotation }\end{array}$ \\
\hline \multirow{3}{*}{$\begin{array}{l}\text { Our study } \\
\text { - Women - }\end{array}$} & \multirow{3}{*}{$\begin{array}{l}\text { Optoelectronic } \\
\text { system }\end{array}$} & \multirow{3}{*}{$100 \%$} & Front & $\begin{array}{l}31^{\circ} \text { upward rotation } \\
7^{\circ} \text { posterior tilt } \\
5^{\circ} \text { external rotation }\end{array}$ \\
\hline & & & Sag & $\begin{array}{l}31^{\circ} \text { upward rotation } \\
2^{\circ} \text { posterior tilt } \\
0^{\circ} \text { internal rotation }\end{array}$ \\
\hline & & & $\mathrm{GH}$ rot & $\begin{array}{l}3^{\circ} \text { downward rotation } \\
8^{\circ} \text { anterior tilt } \\
0^{\circ} \text { external rotation }\end{array}$ \\
\hline \multicolumn{5}{|c|}{$\begin{array}{l}\text { Abbreviations: Arm elevation in the frontal plane (Front_elev) - Arm lowering in the frontal plane (Front_low) - } \\
\text { Arm elevation in the sagittal plane (Sag_elev) - Arm lowering in the sagittal plane (Sag_low) - GH internal to } \\
\text { external rotation (GH int/ext rot) - GH external to internal rotation (GH ext/int rot). If no phase is specified, the } \\
\text { results correspond to the mean of both phases. }\end{array}$} \\
\hline
\end{tabular}

